\title{
Linfoma extranodal de células T/NK, tipo nasal. Reporte de
} caso

\section{Extranodal NK/T-cell lymphoma, nasal type. A case report}

\author{
Uriel Pérez-García ${ }^{1 *}$, María I. Arellano-Mendoza ${ }^{1}$, Ana G. Fuentes-Nava ${ }^{1}$, Sofía López-Cordero ${ }^{1}$ y \\ Patricia Mercadillo-Pérez ${ }^{2}$ \\ ${ }^{1}$ Servicio de Dermatología; ${ }^{2}$ Servicio de Dermatopatología. Hospital General de México, Ciudad de México, México
}

\begin{abstract}
Resumen
El linfoma de células T/NK es poco frecuente. Las lesiones cutáneas presentan una gran variabilidad clínica al momento de su presentación, desde neoformaciones tipo placa hasta nódulos o úlceras. Presentamos el caso de una mujer de 46 años que presentó perforación de paladar y nódulos y úlceras no dolorosas en el tronco y las extremidades inferiores. Se realizó abordaje diagnóstico, a descartar micosis profunda, y se realizó biopsia de piel con inmunhistoquímica que confirmó un linfoma de células T/NK extranodal de tipo nasal. Se inició tratamiento por parte de hematología con quimioterapia, pero la sobrevida fue de 4 semanas.
\end{abstract}

Palabras clave: Linfoma. Células T/NK. Neoformación.

\section{Abstract}

Extranodal NK/T cell lymphoma, nasal type is rare and shows clinical variability at presentation from plaque-like, nodules or ulcers. We present the case of a 46-year-old female patient who had a palate perforation; painless nodules and ulcers on the trunk as well as lower limbs. A diagnostic approach was performed to rule out deep mycoses, a skin biopsy was performed with immunohistochemistry, confirming for extranodal T-cell lymphoma, nasal type. Hematological treatment with chemotherapy was initiated, the survival was 4 weeks.

Keywords: Lymphoma. NK/T cells. Neoformation.

\section{Introducción}

El linfoma de células T/NK se encuentra en general en sitios extranodales, comúnmente la nariz, la nasofaringe, la orofaringe, las vías aéreas superiores y el tracto gastrointestinal superior ${ }^{1}$. La primera descripcion de los linfomas T/NK la hizo McBride en 1897², y desde entonces ha recibido otros nombres, como «granuloma letal de la línea media», «linfoma destructivo de la línea media», «linfoma angiocéntrico», "granuloma maligno» y «reticulosis polimórfica» ${ }^{3}$. La Organización Mundial de la Salud (OMS) y la European Organization for Research and Treatment of Cancer (EORTC) clasificaron los linfomas cutáneos en 2005 y después, en 2018, actualizaron la denominación como linfoma primario de células $\mathrm{T}^{4}$. Posteriormente, la misma OMS derivó el
Correspondencia:

*Uriel Pérez-García

E-mail: dr.urielperezgarcia@gmail.com
Disponible en internet: 28-01-2022 Med Cutan Iber Lat Am. 2022;50(1):33-37 www.MedicinaCutanealLA.com 0210-5187/@ 2021 Colegio Ibero Latinoamericano de Dermatología A.C. (CILAD). Publicado por Permanyer. Este es un artículo open access bajo la licencia CC BY-NC-ND (http://creativecommons.org/licenses/by-nc-nd/4.0/) 
término «linfoma extranodal de celulas T/NK, tipo nasal», para evitar confusiones. Por tanto, existen dos variantes clínicas en la vía aerodigestiva superior, nasal y extranasal, y ambas están asociadas al virus de Epstein-Barr (VEB) ${ }^{5}$.

\section{Caso clínico}

Mujer de 46 años, con antecedente de ceguera secundaria a cataratas, inició el padecimiento actual en octubre de 2018 con cuadros repetitivos de sinusitis y recibió tratamiento no especificado, sin mejoría. En diciembre de 2018 presentó perforación de paladar duro no dolorosa, con exudado purulento, por lo que recibió tratamiento antibiótico no especificado, con mejoría parcial, y subsecuente extensión de la perforación al paladar blando. En marzo de 2019 acudió a nuestro servicio para su valoración. En la exploración física se encontró una dermatosis diseminada que afectaba la espalda, las mamas y las extremidades superiores e inferiores, constituida por nódulos subcutáneos, algunos con úlceras con escara en su superficie, ovaladas, de bordes definidos, no dolorosas a la palpación (Figs. 1 y 2). En la cavidad oral presentaba perforacion de paladar duro, no dolorosa, con exudado purulento (Fig. 3). Se encontraron ganglios linfáticos palpables en el cuello y las axilas.

La paciente refirió al menos un episodio de fiebre por semana en los últimos 6 meses, diaforesis nocturna y pérdida de peso no intencionada de al menos el $10 \%$. Se decidió descartar mucormicosis, por lo que se realizó examen directo $(\mathrm{KOH})$ de la lesión del paladar, el cual fue negativo. Las pruebas de laboratorio reportaron leucocitos $3.5 \times 10^{3} / \mu \mathrm{l}$, neutrófilos $2.6 \times 10^{3} / \mu \mathrm{l}$, hemoglobina $10.2 \mathrm{~g} / \mathrm{dl}$, hematocrito $32.9 \%$, volumen corpuscular medio $99.7 \mathrm{fl}$, hemoglobina corpuscular media $31 \mathrm{pg}$, plaquetas $309 \times 10^{3} / \mu \mathrm{l}$, deshidrogenasa láctica 260 y creatinina $0.56 \mathrm{mg} / \mathrm{dl}$.

Se realizó biopsia de piel con la sospecha clínica de probable proceso linfoproliferativo. En el estudio histopatológico con hematoxilina y eosina se encontró, en la dermis reticular y el tejido celular subcutáneo, un infiltrado inflamatorio angiocéntrico e interlobulillar, constituido por células linfoides con pleomorfismo e hipercromatismo marcado; los vasos presentaron angiodestrucción y necrosis (Figs. 4 y 5). En la inmunohistoquímica se encontró positividad para CD2, CD3, CD8, CD30, TIA-1 y LMP-1, y fue negativa para CD56. Por lo anterior, se diagnosticó linfoma de células T/NK extranodal diseminado, tipo nasal, en estadio IV y de

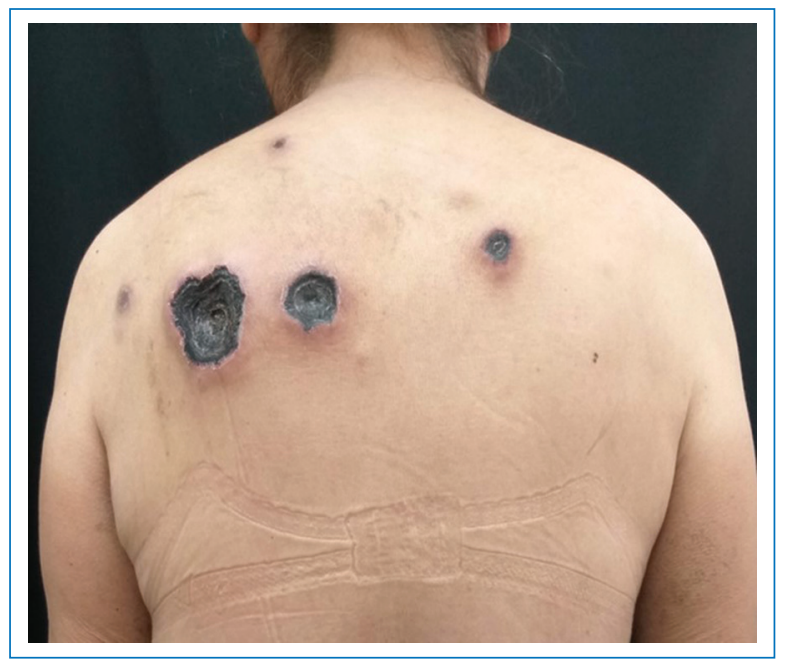

Figura 1. Presencia de múltiples placas con necrosis y nódulos subcutáneos.

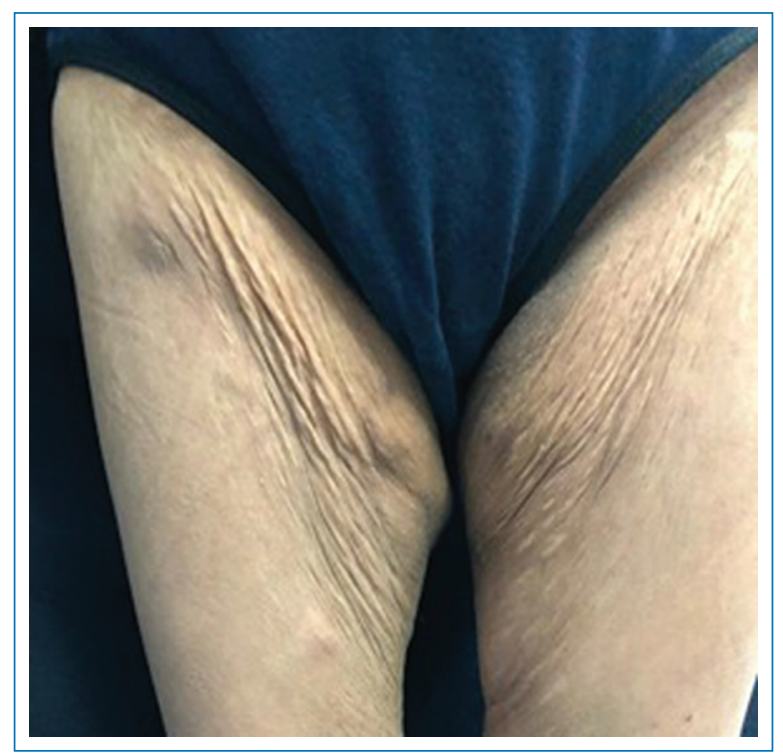

Figura 2. Nódulos subcutáneos en las extremidades inferiores.

alto riesgo según la clasificación de PINK (Prognostic Index of Natural Killer cell lymphoma).

La paciente fue hospitalizada en el servicio de hematología. Se le realizó una tomografía computada simple y contrastada que reportó actividad ganglionar en el cuello y el mediastino relacionada con un proceso linfoproliferativo. Se inició quimioterapia con protocolo SMILE (dexametasona, metotrexato, ifosfamida y L-asparginasa). No se realizaron biopsia ni aspirado de médula ósea por el estado delicado de la paciente al iniciar la quimioterapia. Durante la hospitalizacion, la 


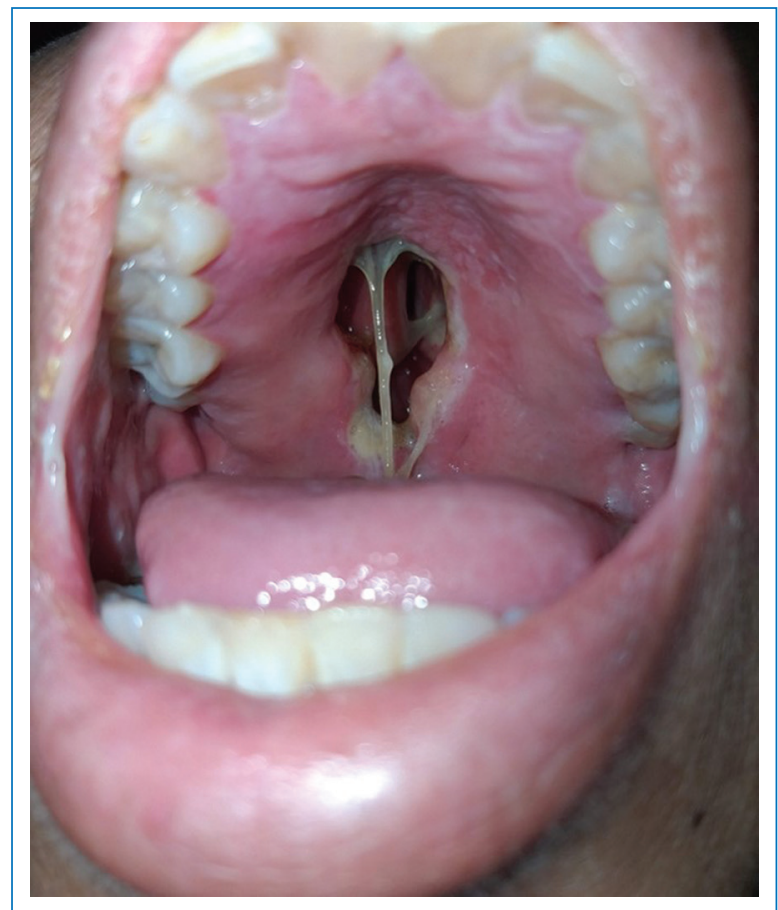

Figura 3. Perforación de paladar duro y blando.

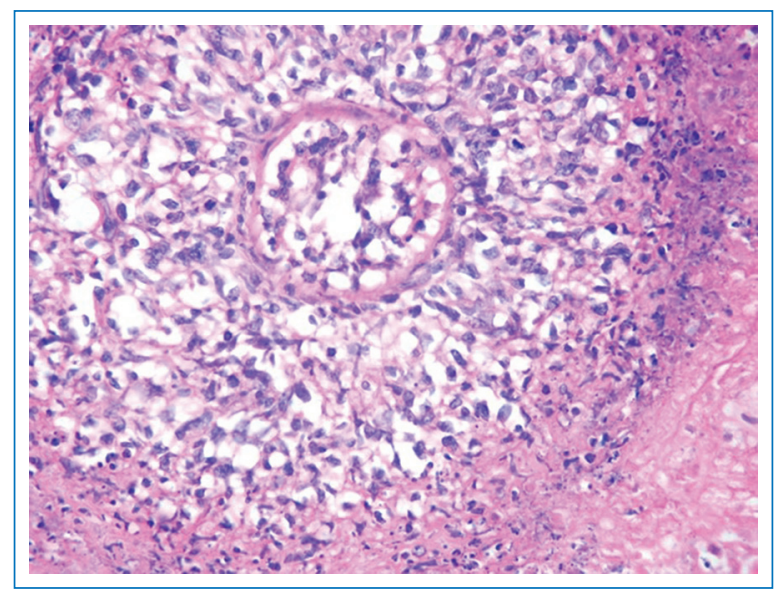

Figura 4. Angiodestruccion, con necrosis, rodeada de infiltrado linfoide con pleomorfismo e hipercromatismo nuclear intenso.

paciente presentó neutropenia febril y choque séptico secundario a Escherichia coli BLEE, y desafortunadamente falleció.

\section{Discusión}

El linfoma extranodal T/NK puede dividirse en dos tipos: nasal y extranasal. El tipo nasal es más frecuente como enfermedad localizada (80\%), mientras que la

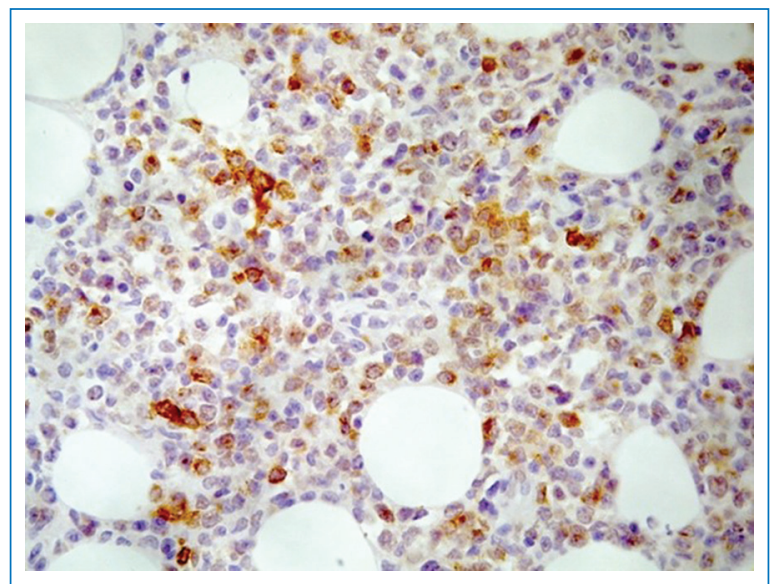

Figura 5. Estudio de inmunohistoquímica positivo para LMP-1.

variante extranasal se detecta con más frecuencia en estadios avanzados $(60 \%)$ y puede presentarse en la piel, el tracto gastrointestinal, los testículos o las glándulas salivales ${ }^{6}$. El linfoma extranodal T/NK representa el $10 \%$ de los linfomas no Hodgkin en Asia y Latinoamerica. Su incidencia en los países del Sudeste asiático y de América Central y del Sur es del $5.2 \%$ y el $3 \%$, respectivamente, mientras que en Norteamerica y Europa apenas es del $0.3 \%$. Generalmente se presenta en adultos (50-60 años de edad) y predomina en el sexo masculino $(2: 1)^{7}$. La supervivencia a 5 años es de aproximadamente el $54 \%$ en los pacientes con linfoma extranodal T/NK tipo nasal y del $34 \%$ en aquellos con la variante extranasal ${ }^{8}$.

En México existen pocos estudios epidemiológicos para determinar la incidencia y la prevalencia del linfoma extranodal T/NK, pero hay reportes de $\operatorname{casos}^{9,10}$.

Se han encontrado alteraciones en genes supresores, como TP53, DDX3X y MGA, así como en la vía JAK/STAT, y alteraciones epigenéticas en MLL2 y $\mathrm{BCOR}^{11}$.

Histológicamente, las celulas de linfoma muestran angiocentricidad y angiodestrucción, resultando en necrosis. Son CD2+, CD3- superficial, citoplasmático $\mathrm{CD} 3 \varepsilon+, \mathrm{CD} 56+$, moleculas citotóxicas como perforina, granzima B y TIA1+. En el estudio histológico, las células de linfoma asemejan linfocitos gigantes granulares $^{12}$. Existe evidencia de infección por el VEB en las células de linfoma, que generalmente infecta las células $B$ a través del receptor CD21, el cual se une a glucoproteínas gp350/220 del virus. Las células natural killer infectadas secretan interleucinas 2 y 9 , que activan e inducen su proliferación. Dentro de las células, 
el VEB persiste en forma episomal, no integrado al genoma del hospedero. EI VEB tiene tres patrones de latencia; el patron tipo II es el más frecuente asociado a linfoma extranodal T/NK y está caracterizado por la expresion de las proteínas virales EBNA1 y LMP1 ${ }^{13}$.

Las lesiones en la piel están presentes en un 16-22\% de casos de linfoma extranodal T/NK. Se pueden presenta como nódulos o placas que pueden ulcerarse, y principalmente afectan las extremidades y el tronco $0^{6,12}$. Esto coincide con el caso presentado, aunque cabe destacar la ausencia de dolor de sus lesiones y, por tanto, el retraso en la búsqueda de atención médica.

El diagnóstico se basa en la exploracion física. Se deben excluir causas más frecuentes de destruccion nasal, como mucormicosis, infecciones bacterianas y otras enfermedades linfoproliferativas, y del mismo modo descartar otras causas de las lesiones cutáneas. Se requiere hacer biopsia de los sitios afectados (nariz, cavidad nasal, órbita, glándulas salivales, senos paranasales, piel). En nuestra paciente solo fue posible realizar la biopsia de piel; la region nasal no se pudo biopsiar por el estado clínico de la paciente. La evaluacion inicial debe incluir biometría hemática, química sanguínea y cuantificación sérica de ADN del VEB. También se requieren estudios de imagen, tomografia computarizada y tomografía por emision de positrones, que sirven para estadificar la enfermedad, tener un basal, realizar controles y para el final del tratamiento.

El linfoma extranodal T/NK diseminado involucra múltiples organos (piel, ganglios, hígado, bazo, médula osea, sangre periférica). Puede presentarse con una fase leucémica y en estos casos es fatal con rápida progresión. La biopsia debe realizarse para identificar la presencia de RNA codificado del VEB por hibridacion in situ dentro de las celulas. Generalmente expresa CD3, CD56, proteínas citotoxicas como granzima B, TIA1, y suele ser negativo para CD3, CD4 y CD5 de superficie $^{14,15}$; todos estos marcadores estuvieron presentes en nuestra paciente.

Se utiliza el PINK como modelo pronóstico para pacientes con linfoma extranodal T/NK. Los factores de riesgo independientes de esta escala son la edad mayor de 60 años, la etapa clínica III o IV, el involucro de ganglios distales y la enfermedad no nasal. Este modelo es bastante útil para discriminar pacientes que deben ser tratados en caso de enfermedad avanzada $^{15,16}$.

Cerca del $60 \%$ de los pacientes con linfoma extranodal T/NK se presentan en estadios localizados I y II, principalmente en el tracto aerodigestivo superior. La supervivencia a 5 años de los pacientes con linfoma extranodal tipo nasal tratados con esquema $\mathrm{CHOP}$ (ciclofosfamida, doxorubicina, vincristina y prednisona) seguido de radioterapia de campo es menor del $50 \%$. Esto puede deberse a la expresión del gen multidrogorresistente 1/ABCB1. Las guías mas recientes recomiendan tratamiento con radioterapia local para los linfomas extranodales T/NK en pacientes con estadio clínico I; en estadio II con afección de ganglios linfáticos cervicales se agregan L-asparginasa o agentes no multidrogorresistentes (o ambos) en caso de linfoma extranodal con enfermedad avanzada. El tratamiento para enfermedad avanzada, recaída o resistente es el protocolo SMILE (dexametasona, metotrexato, ifosfamida, L-asparginasa y etopósido) o el AspaMetDex (L-asparginasa, metotrexato y dexametasona $)^{17-19}$.

El linfoma extranodal T/NK comparte receptores con otros linfomas. Existen nuevas terapias, como brentuximab vedotin (anti-CD30) conjugado con auristatina $E$, daratumumab (anti-CD38) y pembrolizumab (anti-PD1), que se han reportado como opciones de tratamiento ${ }^{20}$.

\section{Conclusiones}

El diagnóstico de un paciente con linfoma extranodal T/NK nasal o extranasal es raro. Además, el diagnóstico es complicado por la variadad clínica de las lesiones y su similitud con otras patologías frecuentes, como en nuestro paciente, que tardó bastante tiempo en ser diagnosticada y por ello el pronóstico se vió mermado. En este caso, la ausencia de dolor de las lesiones, a pesar de ser ulcerativas, es algo que destaca. Entre los diagnósticos diferenciales se deben descartar micosis profundas, principalmente por la compatibilidad clínica, así como infecciones y causas inflamatorias, por lo que la biopsia de las lesiones es crucial para realizar el adecuado diagnóstico. Por todo lo anterior, ante un paciente con alteraciones visuales y lesiones en varias regiones corporales es imprescindible realizar una exploración física minuciosa y lo más completa posible.

\section{Agradecimientos}

Al servicio de micología, al servicio de dermatopatología y a los residentes del servicio de dermatología.

\section{Financiamiento}

Los autores no recibieron patrocinio para llevar a cabo este artículo. 


\section{Conflicto de intereses}

Los autores declaran no tener ningún conflicto de intereses.

\section{Responsabilidades éticas}

Protección de personas y animales. Los autores declaran que los procedimientos seguidos se conformaron a las normas éticas del comité de experimentación humana responsable y de acuerdo con la Asociación Médica Mundial y la Declaración de Helsinki.

Confidencialidad de los datos. Los autores declaran que han seguido los protocolos de su centro de trabajo sobre la publicación de datos de pacientes.

Derecho a la privacidad y consentimiento informado. Los autores han obtenido el consentimiento informado de los pacientes y/o sujetos referidos en el artículo. Este documento obra en poder del autor de correspondencia.

\section{Bibliografía}

1. Olsen EA. Evaluation, diagnosis, and staging of cutaneous lymphoma Dermatol Clin. 2015;33:643-54.

2. McBride P. Photographs of a case of rapid destruction of the nose and face. J Laryngol Otol. 1991;105:1120.

3. Peck T, Wick MR. Primary cutaneous natural killer/T-cell lymphoma of the nasal type: a report of 4 cases in North American patients. Ann Diagn Pathol. 2015;19:211-5.
4. Kempf W, Zimmermann AK, Mitteldorf C. Cutaneous lymphomas - an update 2019. Hematol Oncol. 2019;37(Suppl 1):43-7.

5. Willemze R, Jaffe ES, Cerroni L, Berti E, Swerdlow SH, Ralfkiaer E, et al. WHO-EORTC classifcation for cutaneous lymphomas. Blood. 2009;105:3768-85

6. Tse E, Kwong YL. The diagnosis and management of NK/T-cell lymphomas. J Hematol Oncol. 2017:10:1-13.

7. Haverkos BM, Pan Z, Gru AA, Freud AG, Rabinovitch R, Xu-Welliver M, et al. Extranodal NK/T cell lymphoma, nasal type (ENKTL-NT): an update on epidemiology, clinical presentation, and natural history in North American and European cases. Curr Hematol Malig Rep. 2016;11:514-27.

8. Fox CP, Civallero M, Ko YH, Manni M, Skrypets T, Pileri S, et al. Survival outcomes of patients with extranodal natural-killer T-cell lymphoma: a prospective cohort study from the international T-cell Project. Lancet Haematol. 2020;7:e284-94

9. Ballinas-Aquino J, Arenas R, Vega-Memije ME, Toussaint-Caire S. Linfoma NK nasal en adolescente. Dermatología CMQ. 2016;14:131-6.

10. Vega-González MTJ, Avilés-Salas A, Pérez-Martínez R, Orozco-Anahuati AP. Linfoma extranodal de células T/NK tipo nasal. Presentación de un caso clínico. Rev Cent Dermatol Pascua. 2017;26:54-9.

11. Zhang $Y$, Li C, Xue W, Zhang M, Li Z. Frequent mutations in natural killer/T cell lymphoma. Cell Physiol Biochem. 2018;49:1-16.

12. Tse E, Kwong YL. NK/T-cell lymphomas. Best Pract Res Clin Haematol. 2019;32:253-61.

13. Saleem A, Natkunam Y. Extranodal NK/T-cell lymphomas: the role of natural killer cells and EBV in lymphomagenesis. Int $\mathrm{J}$ Mol Sci. 2020;21:1501.

14. Tse E, Kwong YL. Diagnosis and management of extranodal NK/T cell lymphoma nasal type. Expert Rev Hematol. 2016;9:861-71.

15. Yamaguchi M, Oguchi M, Suzuki R. Extranodal NK/T-cell lymphoma: updates in biology and management strategies. Best Pract Res Clin Haematol. 2018;31:315-21.

16. Kim SJ, Yoon DH, Jaccard A, Chng WJ, Lim ST, Hong H, et al. A prognostic index for natural killer cell lymphoma after non-anthracycline-based treatment: a multicentre, retrospective analysis. Lancet Oncol. 2016;17:389-400.

17. Yamaguchi M, Suzuki R, Oguchi M. Advances in the treatment of extranodal NK/T-cell lymphoma, nasal type. Blood. 2018;131:2528-40.

18. Suzuki R. NK/T cell lymphoma: updates in therapy. Curr Hematol Malig Rep. 2018;13:7-12.

19. Yamaguchi M, Miyazaki K. Current treatment approaches for NK/T-cell lymphoma. J Clin Exp Hematop. 2017:57:98-108.

20. Hu B, Oki Y. Novel immunotherapy options for extranodal NK/T-cell lymphoma. Front Oncol. 2018;8:1-7. 